\title{
Intrapericardial gossypiboma found 14 years after coronary artery bypass grafting
}

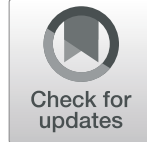

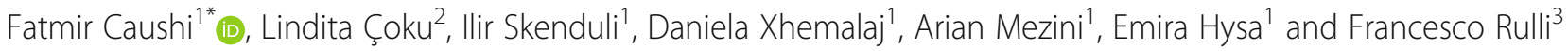

\begin{abstract}
Background: Foreign body left after surgery surrounded by a foreign body reaction otherwise known as gossypiboma, have been first described in 1884. Although it occurs rarely, it can lead to various complications which include adhesions, abscess formation and related complications. Intrathoracic gossypiboma is a rare but serious consequence of negligence, mainly during abdominal and cardiothoracic surgery that can lead to severe medical consequences. This paper aims to raise awareness among surgeons and nurses in the operating room to prevent such errors and future complications.

Case presentation: A patient with a history of coronary arterial bypass grafting performed 14 years ago, presented with shortness of breath and dry cough. A chest X-ray revealed a large mass in the left hemithorax. The chest CT demonstrated the presence of a heterogeneous density mass of $11 \mathrm{~cm}$ and smooth edges in the middle mediastinum, next to the heart and partially intrapericardial. Because clinical and radiologic evidence revealed presence of a mass, we did proceed with CT guided FNA of the mass. The cytology findings confirmed an inflammatory lesion. Based on patient symptomatology and the evidence of a mass, allegedly compressing the cardiopulmonary structures in vicinity, we performed surgical exploration. An old and degraded piece of surgical swap was found and removed through an anterolateral left thoracotomy. The post-operative course was excellent.

Conclusions: Forgetting surgical swaps during surgery is a medical fault. To avoid them, surgical units should design and implement a surgical inventory process to account for surgical instruments or surgical swaps. Failure to make a proper diagnosis of cases such as these can lead to further health complications in these patients. The iatrogenic foreign material seen as a mass in the radiologic films had not been previously noticed by other health professionals although the patient had undergone X-ray and cardiac ultrasound examinations in the 14 years following coronary bypass surgery. Once the causative agent was identified and removed the patient returned to normal activity.
\end{abstract}

Keywords: Gossypiboma, Intrapericardial, Surgery

\section{Background}

Gossypiboma (aka Textiloma), described first in 1884, is a mass within the body composed of a cotton matrix, which usually refers to a retained surgical sponge or swap, surrounded by a foreign body reaction [1]. Although it occurs rarely $(1 / 1000-1500$ abdominal operations), it has significant associated morbidity and mortality. Pathologically, the body response to the foreign body occurs either as an aseptic fibrosis response, or as an exudative reaction resulting in localized abscess formation [2]. Intrathoracic gossypiboma is a rare but

\footnotetext{
* Correspondence: fcaushi@yahoo.com

'Department of Thoracic Surgery, University Hospital "Shefqet Ndroqi", Street

"Shefqet Ndroqi", 1001 Tirana, Albania

Full list of author information is available at the end of the article
}

serious consequence of negligence, mainly during abdominal and cardiothoracic surgery that can have severe medical consequences [1]. The patient with intrathoracic gossypiboma may present symptoms like fever, cough, hemoptysis, weight loss, dyspnea, and shoulder pain [3].

\section{Case presentation}

A 50 year-old male, with a history of coronary arterial bypass grafting 14 years back, presented with shortness of breath and dry cough. An X-ray revealed a large mass in the left hemithorax adjacent to the heart silhouette. A chest CT demonstrated the presence of a mass with smooth edges, in middle mediastinum next to the heart and partially intrapericardial (Fig. 1). The mass was of heterogeneous density and of $11 \mathrm{~cm}$ size. Presence of 


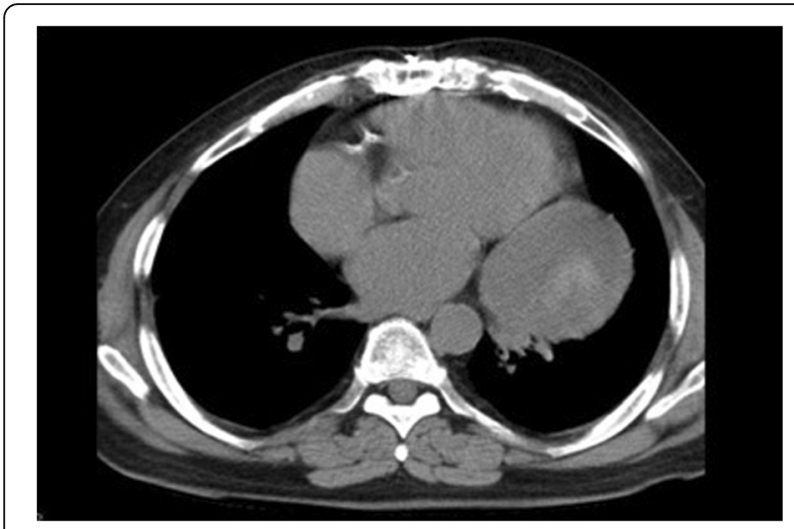

Fig. 1 The Chest CT demonstrates a mass with smooth edges and heterogeneous density, next to the heart and partially intrapericardial

atelectasis at the left lower lobe abating the mass was clearly seen. Based on clinical and radiologic evidence, we did proceed with $\mathrm{CT}$ guided FNA of the mass. The cytology findings revealed inflammatory lesion. Laboratory tests were normal. Based on patient symptoms, history and the presence of a mass potentially compressing the cardiopulmonary structures in vicinity, we decided to offer exploratory surgery for diagnosis and treatment.

Standard hemodynamic monitoring and general anesthesia were followed by positioning, prepping and draping patient in left lateral decubitus position. An anterolateral left thoracotomy was carried out and entrance in the hemithorax was made without any challenge. The mass was assessed and found to be leaning medially on the surface of the lateral wall of the left ventricle, including the pericardial layer and had smooth edges which didn't infiltrate the lung (Fig. 2). We started dissecting the mass from its smooth capsule, making it through all its layers. An old and degraded piece of surgical swap was visualized (Fig. 3). The surgical swap was removed along

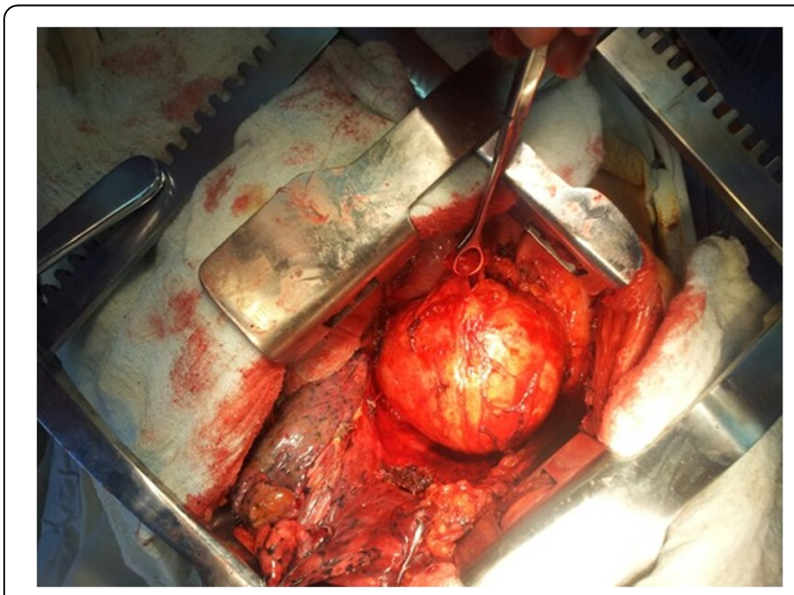

Fig. 2 The view of the mediastinal mass after the left thoracotomy

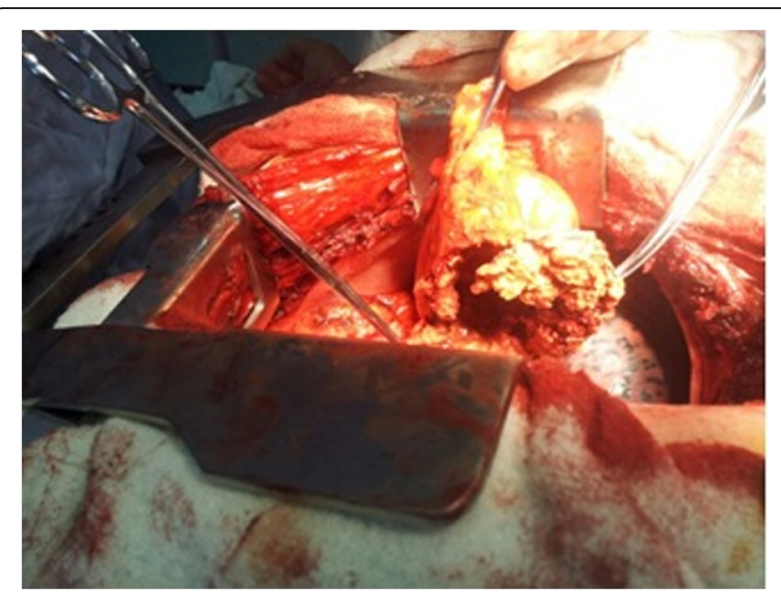

Fig. 3 The presence of an old and degraded piece of surgical swap intrapericardial

with the capsular layer of this mass. Patient tolerated the procedure very well and blood loss was minimal. A chest tube was inserted in the left hemithorax and chest wall was closed following standard procedures.

In the immediate post-operative phase, patient improved steadily and on day four was discharged home symptom-free. In the long-term follow -up, patient was found to remain without symptoms.

\section{Discussion}

Gossypiboma is an important topic and perhaps under reported due to their medicolegal implications [4]. Intrathoracic gossypiboma mainly occurs in pleural and pericardial cavities, with only a few cases of intrapulmonary gossypiboma published [3]. Gossypiboma occurs as a result of extensive wound explorations, errors made during counting, lack of using radio-opaque sponges and misreading postoperative radiologic X-ray graphics [2].

A systematic literature review of 254 gossypiboma case studies, identified via the National Library of Medicine's MEDLINE and the Cochrane Library, revealed that gossypibomas happen most commonly in the abdomen (56\%), pelvis (18\%) and thorax (11\%). Longest reported cases of gossypiboma were found in thorax (43 and 44 years) [5]. There is no clear incidence reported in the literature. An estimated incidence is 1/1000-1/10000 surgeries. The average time to diagnose gossypiboma was 6.9 years and $38 \%$ of the cases are identified within the first year from the surgery $[2,4,6]$.

CT scanning is the most helpful procedure in diagnosing a gossypiboma, especially if a radiopaque marker is used [4]. Wan et al. found that CT was helpful in the diagnosis of $61 \%$ of the cases reviewed, followed by radiography (35\%) and ultrasound (4\%). Pain/irritation (42\%), palpable mass $(27 \%)$, and fever $(12 \%)$ were the leading signs and symptoms while $6 \%$ of cases were 
asymptomatic. Common complications of gossypiboma included adhesion (31\%), abscess formation (24\%), and fistula (20\%) [7].

The CT findings change according to type of foreign material, their anatomical location, and type of reactions they generate in the host [1]. .In the case of a surgical swap, the CT scan typically shows a well-encapsulated mass, usually of low density, with calcified deposits in between the fragments of retained surgical swap, exhibiting the 'calcified reticulate rind' sign, reported previously. Gossypiboma gives a spongiform appearance with gas bubbles, except when it is located in the thorax, when air is resorbed by the surrounding pleura so no gas opacities are seen [2]. In the early postoperative period, the differential diagnosis of gossypiboma includes hematoma and abscess [3]. Following contrast administration, peripheral rim enhancement can be observed [1].

.MRI and biopsy can also be helpful. However, MRI features can be confusing, while biopsy is often indecisive $[4,8]$.

Although rare nowadays, gossypiboma cases do occur. It is clear that leaving unintendedly surgical swaps inside the body during an intervention is a medical liability. Efforts should be made to avoid such iatrogenic errors. Implementing OR checklist pre and post surgery, portable ontable detective rings and strict instrument and sponge count is paramount to prevent such potential catastrophes for patients.

In our case, the radiologic image was initially showing a big mass of mediastinum that involved the pericardium and was accompanied by shortness of breath and dry cough. The history of past surgery in this patient additionally suggested that an intrapericardial foreign body could be producing the current symptoms. We decided to perform the exploratory surgery as the best diagnostic and treatment option because it appeared very well circumscribed.

Although this error didn't happen to us, since this case, we have been more cautious in our surgical practice, counting everything at the beginning of the surgery and before chest closure as described by WHO checklist. We don't close the thorax if something is missing and some time we have used the C-arm to control. We are currently using only surgical swap with radio opaque marker inside.

\section{Conclusions}

Forgetting surgical swaps inside the body during surgery is a preventable medical error that should be avoid at all cost, even in very difficult cases with a high level of tension in the operating room. They can be prevented by implementing a strict patient safety protocol such as an instrument, needle and surgical swaps count procedure before surgery and before closure. Another lesson learned is that in cases such as ours, surgical exploration is the best treatment. Investigating duration of symptoms, the difficulty to make the correct diagnosis by only routine clinical exam prompts us as surgeons to carefully investigate and intervene in timely fashion. As demonstrated, the iatrogenic foreign material seen as a mass in the radiologic films was the culprit of patient's severe symptoms. Once the cause was identified and the foreign body removed, patient returned to normal activity.

It is inexcusable that this patient for 14 years made a lot of medical tests, including yearly X-rays and cardiac ultrasounds and no one has found anything wrong. This case aims to raise awareness among surgeons and nurses in the operating room and doctors in their everyday work to prevent such errors and future complications that may deteriorate patients' health.

\section{Abbreviations \\ CT: Computed Tomography; FNA: Fine Needle Aspiration; MRI: Magnetic Resonance Imaging; OR: Operation Room}

\section{Acknowledgements \\ We want to thank Prof. Michael Muller, Head of Department of Thoracic Surgery at Otto Wagner Hospital of Vienna, who highly suggested preparing this case for publication. \\ Also we want to thank Drs. Dritana Marko for assistance with preparing the manuscript.}

\section{Funding}

All Authors have no source of funding.

\section{Availability of data and materials}

Data sharing is not applicable to this article as no datasets were generated or analyzed during the current study.

\section{Authors' contributions}

FC: Participated substantially in conception, design, and execution of the study; also participated substantially in the drafting and editing of the manuscript. LC: Participated substantially in conception, design, and execution of the study; also participated substantially in the drafting and editing of the manuscript. IS: Participated substantially in conception, design, and execution of the study; also participated substantially in the drafting and editing of the manuscript. DX: Participated substantially in conception, design, and execution of the study; also participated substantially in the drafting and editing of the manuscript. AM: Participated substantially in conception, design, and execution of the study. EH: Participated substantially in conception, design, and execution of the study. FR: Participated substantially in conception, design, and execution of the study. All authors have read and approved the submission of the final manuscript.

Ethics approval and consent to participate

Ethical approval was requested and obtained from the Ethical Committee of University Hospital "Shefqet Ndroqi" of Tirana.

\section{Consent for publication}

Written informed consent was obtained from the patient for publication of this case report and accompanying images. A copy of the written consent is available for review by the Editor-in-Chief of this journal on request.

Competing interests

The authors declare that they have no competing interests. 


\section{Publisher's Note}

Springer Nature remains neutral with regard to jurisdictional claims in published maps and institutional affiliations.

\section{Author details}

'Department of Thoracic Surgery, University Hospital "Shefqet Ndroqi", Street "Shefqet Ndroqi", 1001 Tirana, Albania. ${ }^{2}$ Department of Cardio-Thoracic Surgery, Mount Sinai Hospital, New York, NY, USA. ${ }^{3}$ Department of Surgery, "Our Lady of Good Counsel" University, Tirana, Albania.

Received: 7 February 2019 Accepted: 1 April 2019 Published online: 08 April 2019

\section{References}

1. Koul P, Mufti S, Khan U, Jan R. Intrathoracic gossypiboma causing intractable cough. Interact Cardiovasc Thorac Surg. 2012;14(2):228-30.

2. Hameed A, Naeem A, Azhar M, et al. Intrathoracic gossypiboma. BMJ Case Rep. 2014;2014:bcr2013201814.

3. Bakan S. Intrathoracic Gossypiboma after spinal operation. Ann Thorac Surg. 2015;99(2):e37-9.

4. Pisal N, Sindos M, Henson G. Risk factors for retained instruments and sponges after surgery. N Engl J Med. 2003;348:1724-5.

5. Taylor FH, Zollinger RW 2nd, Edgerton TA, Harr CD, Shenoy VB. Intrapulmonary foreign body: sponge retained for 43 years. J Thorac Imaging. 1994 Winter;9(1):56-9.

6. Hyslop JW, Maull KI. Natural history of the retained surgical sponge. South Med J. 1982;75:657-60.

7. Wan W, Le T, Riskin L, et al. Improving safety in the operating room: a systematic literature review of retained surgical sponges. Curr Opin Anaesthesiol. 2009;22:207-14.

8. Manzella A, Filho PB, Albuquerque E, et al. Imaging of gossypibomas: pictorial review. AJR Am J Roentgenol. 2009;193(6 Suppl):S94-101.

Ready to submit your research? Choose BMC and benefit from:

- fast, convenient online submission

- thorough peer review by experienced researchers in your field

- rapid publication on acceptance

- support for research data, including large and complex data types

- gold Open Access which fosters wider collaboration and increased citations

- maximum visibility for your research: over $100 \mathrm{M}$ website views per year

At BMC, research is always in progress.

Learn more biomedcentral.com/submissions 